\title{
REFORMAS DA DISCIPLINA LÍNGUA PORTUGUESA EM MATO GROSSO DO SUL (1977-2008)
}

\author{
Estela Natalina Mantovanni Bertoletti (UEMS/UNESP/Araraquara)
}

\begin{abstract}
Resumo
Este texto apresenta e socializa pesquisa de pós-doutorado vinculada à UNESP/Araraquara, cujo tema é a história do ensino de língua portuguesa em Mato Grosso do Sul e tem como objetivos: analisar as normatizações empreendidas nos currículos de $1^{\circ}$ grau/ensino fundamental prescritos para essa disciplina no estado em questão, desde 1977 - ano de criação do estado - até 2008 - ano de publicação do mais recente documento oficial para esse ensino no estado, para compreender essa história do ponto de vista oficial. Para isso, forma eleitos como corpus documentos oficiais que normatizam o ensino de língua portuguesa no estado de Mato Grosso do Sul para, por meio da análise da configuração textual desses documentos, alcançar os objetivos propostos. Trata-se de pesquisa histórica em Educação que segue a tendência teóricometodológica nomeada História Nova/História Cultural que concebe a escola dotada de uma cultura própria e as disciplinas, uma das produções ou criações próprias da escola.
\end{abstract}

\section{Palavras-chave}

Língua Portuguesa: história. Língua Portuguesa: ensino. Língua Portuguesa: disciplina

\begin{abstract}
This paper presents and socialize research pos-doctor linked to UNESP/Araraquara, whose theme is the history of teaching English in Mato Grosso do Sul and aims to: examine the norms implemented in the curriculum of 1 st grade/elementary school prescribed for this discipline in the state in question since 1977 the year of creation of the state - until 2008 - the year of publication of the latest official document to that school in the state, to understand this history of official point of view. The corpus is official documents that regulate the teaching of Portuguese in the state of Mato Grosso do Sul for, by analyzing the configuration of these textual documents, to achieve the proposed objectives. This is historical research in education that follows the trend theoretical and methodological named New History/Cultural History that sees school endowed with its own culture and the disciplines, one of the productions or school's own creations.
\end{abstract}

Key-words

Portuguese: history. Portuguese: teaching. Portuguese: discipline.

\section{Introdução}

Este texto apresenta pesquisa de pós-doutorado vinculada à Universidade Estadual Paulista (UNESP), campus de Araraquara, iniciada em fevereiro de 2010, sob supervisão da professora $\operatorname{Dr}^{\mathrm{a}}$ Rosa Fátima de Souza, cujo tema é a história do ensino de língua portuguesa em Mato Grosso do Sul. Nele, além de apresentar o tema, o problema e sua justificativa e os aspectos teórico-metodológicos da pesquisa, apresento análise preliminar dos documentos eleitos como corpus.

\section{O tema, seu problema e sua justificativa}

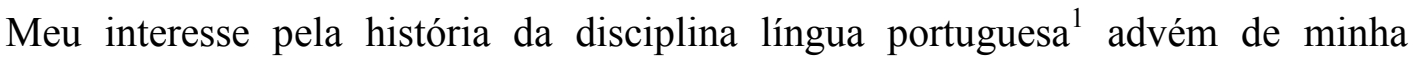
formação inicial em Letras e de meu envolvimento em pesquisas de fundo histórico,

\footnotetext{
${ }^{1}$ Embora essa não seja a única denominação dada a esta disciplina, ao longo do tempo, optei por "língua portuguesa" sempre que me referir ao tema desta pesquisa, respeitando, no entanto, a denominação utilizada nos documentos de época, que oscila entre: "português", "comunicação e expressão", "língua nacional", "língua portuguesa", dentre outras.
}

\begin{tabular}{|l|l|l|l|l|l|}
\hline Interfaces da Educ. & Paranaíba & v. 1 & n. 2 & p. 55-68 & 2010 \\
\hline
\end{tabular}


desenvolvidas junto ao Programa de Pós-Graduação em Educação, na UNESP/Marília, vinculadas ao Grupo de Pesquisa "História do Ensino de Língua e Literatura no Brasil" $(G P H E L L B)^{2}$ e ao Projeto Integrado de Pesquisa "Ensino de língua e literatura no Brasil: repertório documental republicano" (PIPELLB) ${ }^{3}$, sobre as contribuições de Manoel Bergström Lourenço Filho (1897-1970) para a educação brasileira no âmbito da alfabetização ${ }^{4}$ e da literatura infantil e juvenil ${ }^{5}$.

O desenvolvimento dessas pesquisas apontou para um conjunto de temas e problemas relativos à história do ensino de língua e literatura no Brasil que continuam pouco ou quase nada explorados, e especialmente apontou para a falta de estudos e pesquisas que contemplem diferentes estados da nação, dentre eles, o de Mato Grosso do Sul (MS). Em outras palavras, pude perceber que, embora, no Brasil, as pesquisas de fundo histórico venham ganhando abrangência e prestígio acadêmicos cada vez maiores, uma vez que se vêm firmando como uma tendência teórico-metodológica bastante fecunda no âmbito das ciências humanas em geral e da educação em particular (MORTATTI, 1999), continuam, por exemplo, ainda pouco ou quase nada exploradas as relativas à história da disciplina língua portuguesa no estado de Mato Grosso do Sul, dentre outros aspectos.

\footnotetext{
${ }^{2}$ O GPHELLB, coordenado pela professora Dra Maria do Rosário Longo Mortatti, do qual sou membro, entrou em atividade em 1994 e permanece em funcionamento até os dias atuais, estando cadastrado no Diretório dos Grupos de Pesquisa do Brasil (CNPq) e certificado pela UNESP.

${ }^{3}$ O PIPELLB (apoio e auxílio financeiro CNPq; auxílio FAPESP), do qual fui membro da equipe executora, foi desenvolvido entre agosto de 1999 e julho de 2003 e derivado das atividades do GPHELLB. Teve como objetivo geral organizar, ampliar, sistematizar e divulgar, por meio impresso e eletrônico, uma obra de referência, com caráter de repertório de fontes documentais produzidas entre as últimas décadas do século XIX e os dias atuais, relativa às suas cinco linhas de pesquisa: 1. Formação de Professores de Língua e Literatura; 2. Alfabetização; 3. Ensino de Língua Portuguesa; 4. Ensino de Literatura; e 5. Literatura Infantil e Juvenil. A obra de referência resultante das atividades desse projeto contém um total de 2.025 referências distribuídas entre suas cinco linhas de pesquisa e encontra-se disponível no acervo do GPHELLB.

${ }^{4}$ Dessa pesquisa resultou a Dissertação de mestrado intitulada Cartilha do povo e Upa, cavalinhol - o projeto de alfabetização de Lourenço Filho (1997). Nela, mediante análise da configuração textual de ambas as cartilhas, cujas primeiras edições datam de 1928 e 1957, respectivamente, busquei compreender e explicar o projeto de alfabetização de Lourenço Filho, concluindo que esse projeto foi reiterado por Lourenço Filho ao longo do tempo, passando por poucas modificações e atualizações e adquirindo um caráter de permanência e sucesso que lhe garantiu durabilidade e presença até os dias atuais. Com adequação de redação, os resultados da pesquisa foram publicados no livro: Lourenço Filho e a alfabetização: um estudo de Cartilha do povo (1928) e da cartilha Upa, cavalinho! (1957), pela Editora UNESP, em 2006.

5 Dessa pesquisa resultou a Tese de doutorado intitulada A produção de Lourenço Filho sobre e de literatura infantil e juvenil (1942-1968): fundação de uma tradição que teve por objetivos: contribuir para a produção de uma história, teoria e crítica específicas da literatura infantil e juvenil brasileiras; compreender a produção de Lourenço Filho sobre e de literatura infantil e juvenil, mediante análise da configuração textual do corpus eleito; e compreender a relação entre essa produção e o lugar ocupado por seu autor no âmbito da história da literatura infantil e juvenil brasileira. Foi possível concluir que, em sua produção sobre e de literatura infantil e juvenil, Lourenço Filho funda uma tradição, característica de determinada época, que serve de referência a seus pósteros, influenciando sobremaneira a produção sobre e de literatura infantil e juvenil até os dias atuais.
}

\begin{tabular}{|l|l|l|l|l|l|}
\hline Interfaces da Educ. & Paranaíba & v. 1 & n. 2 & p. 55-68 & 2010 \\
\hline
\end{tabular}


No que se refere aos estudos e pesquisas institucionais e acadêmicos sobre a história dessa disciplina no Brasil, vêm-se intensificando nas duas últimas décadas, mas são ainda escassos (MORTATTI, 2003), e abordam predominantemente o estado de São Paulo ${ }^{6}$.

Com relação ao período delimitado nesses estudos e pesquisas que abordam o tema indicado, observei, também, certa ênfase ao final do século XIX e anos iniciais do século $\mathrm{XX}$, havendo certa escassez de abordagens que busquem compreensão do passado mais recente, sobretudo, após os anos de 1970 até nosso presente histórico. Em vista disso, o estado de Mato Grosso do Sul, criado em 1977, tem sido pouco abordado nesses estudos e pesquisas. Entretanto, Mato Grosso do Sul, com pouco mais de trinta anos de criação, tem também uma história. Que história é essa? Relativamente às questões de língua e literatura, como foi se configurando uma cultura sul-mato-grossense? Quais as influências recebidas? Quem contribuiu para a concretização dessas questões no estado? De quais lugares?

A partir destas constatações e questões, interessei-me em investigar a história da disciplina língua portuguesa em Mato Grosso do Sul, enfocando a oficialização de seu ensino no currículo, materializado nas propostas curriculares, desde a criação do estado em 1977 até 2008, ano de publicação da mais recente proposta curricular do estado, para investigar: quais as normatizações ${ }^{7}$ empreendidas nos currículos para o ensino da disciplina língua portuguesa em Mato Grosso do Sul?

E mais: quais concepções para o ensino de língua portuguesa foram oficializadas nas propostas curriculares em Mato Grosso do Sul? Quais as correntes teóricas que sustentam essas concepções? Como essas concepções foram materializadas nas propostas? Para qual demanda essas propostas curriculares se dirigiam? A que finalidades e necessidades da época os currículos respondiam? Quais as possíveis relações podem ser estabelecidas entre as diferentes propostas curriculares ao longo do tempo? As reformas na disciplina de língua portuguesa corresponderam a mudanças e/ou inovações no ensino dessa disciplina?

\footnotetext{
${ }^{6}$ Com essa afirmação não quero dizer que outros estados da nação não venham se ocupando de construir uma história específica desse tema em seu estado, como, por exemplo, Minas Gerais e Mato Grosso, no entanto, quero ressaltar a grande expansão dessas pesquisas sobre o estado de São Paulo.

${ }^{7}$ O uso do termo "normatizações" e suas variações foram inspiradas em Mortatti (2000), que o utilizou em relação ao conteúdo, finalidades e forma de veiculação de documentos relativos à alfabetização, além dos termos "tematizações" e "concretizações". Neste texto, adaptei-o aos documentos escolhidos como corpus, relativos à disciplina língua portuguesa.
}

\begin{tabular}{|l|l|l|l|l|l|}
\hline Interfaces da Educ. & Paranaíba & v. 1 & n. 2 & p. 55-68 & 2010 \\
\hline
\end{tabular}


A escolha pelo estado de Mato Grosso do Sul se justifica pelos motivos expostos, relativos à falta de estudos e pesquisas, mas também por meu envolvimento direto com esse estado, no desenvolvimento e orientação de estudos e pesquisas sobre a realidade local, sobretudo, relativos à alfabetização, à literatura infantil e juvenil e ao ensino de língua e literatura, como uma de minhas funções na Universidade Estadual de Mato Grosso do Sul (UEMS), onde tenho trabalhado desde 1994. Essa escolha, no entanto, não desconsidera seus laços com o estado de Mato Grosso, pois em história não há ruptura, mas um movimento complexo, cujo ritmo caracteriza-se pela continuidade de movimentos e descontinuidade de sentidos, num movimento em vórtice (MORTATTI, 2000a). Deve-se ao intuito de traçar uma história específica do estado de Mato Grosso do Sul, a partir da realidade configurada para a disciplina língua portuguesa, buscando uma identidade também específica, a qual, muitas vezes, vai se entrelaçar à história daquele estado. $\mathrm{O}$ ano de encerramento da coleta de documentos deve-se somente a uma delimitação necessária.

A opção pela análise das propostas curriculares para o ensino de língua portuguesa, apoia-se na necessidade, apontada por Geraldi, Silva e Fiad (1996) e Marinho (2001), de uma investigação analítica das propostas curriculares dos estados da nação (o que constatei, tem sido feito, especialmente sobre as do estado de São Paulo), uma vez que, segundo os primeiros, qualquer retrospectiva a propósito do ensino de língua portuguesa torna-se temerária, se não se fundamentar sobre esse tipo de investigação. E, de acordo com Marinho (2001), do ponto de vista da história da disciplina língua portuguesa, “[...] o estudo dos objetos, dos materiais e das práticas escolares referentes ao ensino de português incluiria os currículos [...] os quais constroem conteúdos e concepções para essa disciplina” (MARINHO, 2001, p. 28).

Em vista disso, a abordagem do tema, envolvido com a cultura escolar, relativa ao ensino de língua portuguesa, não contempla as práticas escolares, mas o posicionamento oficial diante dessa disciplina, as normatizações para seu ensino, de modo a proceder a uma avaliação mais pragmática do que se pode conceber como um conjunto de pressupostos desejáveis e que constituem um discurso hegemônico sobre o ensino da língua, atravessando as práticas escolares e se fazendo presente nas diversas vozes que se ocupam desse ensino. 


\section{O referencial teórico-metodológico}

Atualmente, a pesquisa histórica em Educação tem seguido uma tendência teóricometodológica nomeada História Nova/História Cultural originada na França em 1929, com a publicação do periódico Annales d'historie économique et sociale, associada à escola de Annales, liderada por Marc Bloch e Lucien Febvre, como um movimento que se contrapunha ao paradigma da historiografia tradicional.

Caracterizada por um movimento sinuoso de constituição, de sua origem até o momento atual, por deslocamento temático e descontinuidade metodológica, a História Nova propiciou a ampliação da acepção de fontes e de critérios de análise dos documentos.

Com efeito, de uma história da educação, durante muito tempo, essencialmente institucional e ideológica (CHARTIER, 1990), passou-se a priorizar campos de trabalho

[...] numerosos para uma história que já não confunde os discursos sobre educação com os reais processos educativos e que pode propor (uma vez clarificados a função e funcionamento da escola em seus diferentes níveis) um novo exame dos antigos interesses: as teorias e projectos pedagógicos, os métodos de ensino, os conteúdos ensinados. (CHARTIER, 1990, p. 162).

Dessa forma, certos temas passaram a ser privilegiados e a escola, grande fonte para a produção da história da educação, passou a objeto histórico, considerada no que se convencionou a se considerar cultura escolar.

Para Andre Chervel (1990), a escola é dotada de uma cultura própria que não somente forma o indivíduo, mas também forma uma cultura que penetra, molda e modifica a cultura da sociedade. Não se trata, portanto, de uma escola reprodutora de conteúdos de ensino a ela impostos pela sociedade e pela cultura que a rodeiam.

Segundo Dominique Julia (2001), cultura escolar é

[...] um conjunto de normas que definem conhecimentos a ensinar e condutas a inculcar, e um conjunto de práticas que permitem a transmissão desses conhecimentos e a incorporação desses comportamentos; normas e práticas coordenadas a finalidades que podem variar segundo as épocas [...] (JULIA, 2001, p. 10, grifos do autor).

Em vista disso, para esse mesmo autor, a cultura escolar não pode ser estudada sem o exame das relações conflituosas ou pacíficas que ela mantém em sua época com o conjunto de culturas que lhe são contemporâneas, uma vez que, os historiadores da educação apresentam uma tendência a superestimar modelos e projetos e a constituir essa cultura " $[. .$.$] como um isolamento, contra o qual as restrições e as contradições do mundo$

\begin{tabular}{|l|l|l|l|l|l|}
\hline Interfaces da Educ. & Paranaíba & v. 1 & n. 2 & p. 55-68 & 2010 \\
\hline
\end{tabular}


exterior viriam a se chocar [...]" (JULIA, 2001, p. 12), e, ainda, desprezam “[...] as resistências, as tensões e os apoios que os projetos têm encontrado no curso de sua execução", porque compartilham a convicção de "[...] uma escola todo-poderosa, onde nada separa intenções de resultados". (JULIA, 2001, p. 12).

Para resolver o que chama de ilusão, Julia (2001) aponta que convém olhar o funcionamento interno da escola, por meio da história das disciplinas escolares que

[...] tenta identificar, tanto através das práticas de ensino utilizadas na sala de aula como através dos grandes objetivos que presidiram a constituição das disciplinas, o núcleo duro que pode constituir uma história renovada da educação. Ela abre, em todo caso, para retomar uma metáfora aeronáutica, a 'caixa preta' da escola, ao buscar compreender o que ocorre nesse espaço particular. (JULIA, 2001, p. 13, grifos do autor).

Isso porque, as disciplinas escolares são entidades sui generis, próprias da escola, “[...] independentes, numa certa medida, de toda realidade cultural exterior à escola, e desfrutando de uma organização, de uma economia interna e de uma eficácia que elas não parecem dever nada além delas mesmas, quer dizer à sua própria história" (CHERVEL, 1990, p. 180).

Citando André Chervel (1988), Julia (2001) explica que as disciplinas escolares são inseparáveis das finalidades educativas, no sentido amplo do termo " escola", e constituem "[...] um conjunto complexo que não se reduz aos ensinos explícitos e programados" (CHERVEL, 1988, apud JULIA, 2001, p. 33), por isso aponta a necessidade de se examinar a evolução dessas disciplinas, levando-se em conta:

[...] os conteúdos ensinados, os exercícios, as práticas de motivação e de estimulação dos alunos, que fazem parte destas 'inovações' que não são vistas, as provas de natureza quantitativa que asseguram o controle das aquisições (JULIA, 2001, p. 34, grifos do autor).

Com a ampliação das fontes documentais, sobretudo anteriormente representadas por textos normativos, o historiador que "[...] sabe fazer flechas com qualquer madeira" (JULIA, 2001, p. 17) pode reconstituir, na falta de documentos do cotidiano escolar, "[...] indiretamente, as práticas escolares a partir de normas ditadas nos programas oficiais" (JULIA, 2001, p. 17), haja vista que, consegue atingir "[...] mais facilmente os textos reguladores e os projeto pedagógicos que as próprias realidades”( JULIA, 2001, p. 19), no entanto, estes devem sempre reenviar às práticas por eles legitimadas. 
Compreender o cotidiano de uma escola, portanto, exige um mergulho profundo em seus aspectos internos, no ambiente externo no qual estava imersa durante o período analisado e em sua estrutura organizacional, bem como nos modelos e práticas educativas que lhe conferem identidade. Na investigação da história da disciplina língua portuguesa, portanto, é importante atentar para os diferentes aspectos que configuram seu currículo, aspectos que se articulam e se entrelaçam, procurando analisar qual o sentido conferido a todos esses elementos em seu conjunto.

Assim, concebo as disciplinas escolares como reguladas por elementos internos e externos (SANTOS, 1990), nos quais os primeiros elementos relacionam-se a fatores de uma escala micro, ou seja, às condições de trabalho na área, por exemplo, e os últimos têm estreita relação com aspectos de uma escala macro, como as políticas educacionais e o contexto socioeconômico sem, no entanto, considerá-los dissociados ou contextuais, apenas.

$\mathrm{Na}$ análise das fontes, Julia (2001), exemplificando com análises de manuais didáticos, realça a necessidade de não se proceder a análises puramente ideológicas, que, a seu ver, levam ao anacronismo, sendo, portanto, mais conveniente, recontextualizá-las em sua circunstância histórica.

Como se pode depreender, optei por uma abordagem histórica do tema investigado, que se baseia em uma concepção de História que leva em conta toda experiência humana como história real construída por homens reais "[...] vivendo relações de dominação e resistência". (VIEIRA; PEIXOTO; KHOURY, 1991, p. 17-18). Desse ponto de vista, a produção do conhecimento

[...] é capaz de apreender e incorporar essa experiência vivida, fazer retornar homens e mulheres não como sujeitos passivos e individualizados, mas como pessoas que vivem situações e relações sociais determinadas com necessidades e interesses e com antagonismos. (VIEIRA; PEIXOTO; KHOURY, 1991, p. 17$18)$.

Isso não significa, como adverte Marc Bloch (s.d.), buscar "resgatar" a "verdade", como uma "ingênua ilusão", mas buscar conhecer os fatos como se passaram (BLOCH, s.d.), interpretando o discurso perante sua relação com a "verdade", tendo o documento como suporte de possibilidades e de limites da interpretação historiográfica (BOTTO, 1994).

É importante frisar que a abordagem de fundo histórico não visa ao julgamento de valor, nem à assunção do ponto de vista defendido pelos sujeitos envolvidos, nem à

\begin{tabular}{|l|l|l|l|l|l|}
\hline Interfaces da Educ. & Paranaíba & v. 1 & n. 2 & p. 55-68 & 2010 \\
\hline
\end{tabular}


exorcização do passado. Seu objetivo é compreender — para explicar — fatos e fenômenos que, no caso específico, envolvem a história da disciplina língua portuguesa, investigada em documentos oficiais para seu ensino.

A abordagem histórica do tema está centrada em pesquisa documental e bibliográfica, desenvolvida mediante procedimentos de localização, seleção e ordenação de fontes primárias (documentos impressos oficiais) e secundárias (bibliografia sobre o tema nos anos em estudo ou em anos pósteros).

A reunião do conjunto desses elementos que se organizam e se entrelaçam, permite a análise da configuração textual dessas fontes documentais. Esse tipo de análise permite abordar a identidade dos documentos em sua natureza e especificidade, ou seja, os documentos são textos assumidos como ponto de partida e de chegada do processo interpretativo, que materializam um projeto discursivo,

[...] concebido, executado e avaliado por um sujeito que, a partir de certas necessidades, movido por certos objetivos, sobressaltado pelas contingências e mediado pela linguagem, em determinadas condições históricas e sociais, escolhe — dentre as possíveis e conhecidas — as opções de dizer/escrever o que precisa escrever para outro (s). (MORTATTI, 2000b, p. 14-15).

Desse ponto de vista,

[...] o que confere singularidade a um texto é o conjunto de aspectos constitutivos de sua configuração textual, a saber: as opções temáticoconteudísticas (o quê?) e estruturais-formais (como?) projetadas por um determinado autor (quem?), que se apresenta como sujeito de um discurso produzido de determinado ponto de vista e lugar social (de onde?) e momento histórico (quando?) movido por certas necessidades (por quê?) e propósitos (para quê?) e visando a determinado tipo de leitor previsto (para quem?), assim como a circulação, utilização e repercussão logradas pelo projeto do autor ao longo da história (de leitura) do texto. (MORTATTI, 2000b, p. 15).

Como se pode perceber, o método de análise da configuração textual permite a apreensão do sentido do texto a partir de seus diferentes aspectos. Não se trata, no entanto, de reduzir o processo analítico a aspectos isolados da configuração textual ou ainda a aspectos externos do texto. Trata-se de "encontrar" os sentidos e as explicações no conjunto de aspectos constitutivos da configuração do texto.

\section{Alguns resultados parciais}

$\mathrm{Na}$ fase de coleta de material documental, verifiquei que são escassos os documentos relativos aos anos de 1970, em virtude, especialmente, do período de transição

\begin{tabular}{|l|l|l|l|l|l|}
\hline Interfaces da Educ. & Paranaíba & v. 1 & n. 2 & p. 55-68 & 2010 \\
\hline
\end{tabular}


político-administrativa do estado de Mato Grosso para o de Mato Grosso do Sul. A situação do magistério estadual era precária, formado por muitos professores leigos e por gestores profissionais liberais alheios à educação, por congelamento salarial e atrasos nos pagamentos, dialogando com a repressão nacional, resultante do regime militar ditatorial (BIASOTTO; TETILA, 1991).

A consulta a alguns documentos de época, como livros didáticos, provas e cadernos escolares de alunos, que concretizam as normatizações para a disciplina Comunicação e Expressão, vigente desde a promulgação da Lei de Diretrizes e Bases da Educação Nacional (LDB) $\mathrm{n}^{\mathrm{o}} 5.692$, de $1971^{8}$, apontam para a constatação de que a disciplina segue o eixo da função ideológica, centrada no ensino do falar e escrever bem e corretamente, por meio da sistematização gramatical. À época, no entanto, há um aumento progressivo da escolarização e, em consequência, diversas linguagens adentram as salas de aula que repercutem, pelo menos, de duas formas: em adequação da linguagem aos novos alunos ou em reprovação em massa nas primeiras séries de cada curso.

Mato Grosso do Sul passa a ter autonomia político-administrativa e, por isso, passa a ser considerado separadamente de Mato Grosso nos controles estatísticos, somente a partir de 1980, coincidindo com o período de abertura política e com os ventos da democracia. Porém, somente em 1989 é publicado o primeiro documento que prescreve o currículo de todas as matérias do núcleo-comum para as escolas públicas do estado. Tratase de Diretrizes Gerais para o ensino de pré-escolar e de $1^{\circ}$ grau, no qual a disciplina Português ocupa lugar de destaque, seja pelo número maior de páginas do que o das outras disciplinas seja pelas inovações propostas em relação à disciplina Comunicação e Expressão.

Seguindo o normatizado pelo Decreto n ${ }^{\circ} 91.372$ de 26 de junho de 1985, nas Diretrizes para o aperfeiçoamento do ensino/aprendizagem da língua portuguesa, as Diretrizes Gerais..., no que diz respeito à disciplina Português, centram seu eixo na linguagem como forma de interação humana, em detrimento da linguagem como forma de comunicação. O mesmo pode-se afirmar em relação ao segundo documento eleito para análise: Diretrizes Curriculares Português, Língua Portuguesa e Literatura Brasileira (1º e $2^{\circ}$ graus), de 1992.

\footnotetext{
${ }^{8}$ De acordo com a LDB n ${ }^{\circ} 5.692 / 71$ a disciplina língua portuguesa passa a ser Comunicação e Expressão na $1^{\mathrm{a}}$ a $4^{\mathrm{a}}$ série do ensino de $1^{\mathrm{o}}$ grau e Comunicação e Expressão em Língua Portuguesa de $5^{\mathrm{a}}$ a $8^{\mathrm{a}}$ série, somente sendo denominada Língua Portuguesa e Literatura Brasileira no $2^{\circ}$ grau.
}

\begin{tabular}{|l|l|l|l|l|l|}
\hline Interfaces da Educ. & Paranaíba & v. 1 & n. 2 & p. 55-68 & 2010 \\
\hline
\end{tabular}


Neste, no entanto, não se trata de posicionar-se a partir de uma concepção que se quer combater, mas sim de reiterar e, por isso, aprofundar a concepção interacionista de linguagem. Naquele, destaca-se mais do que o aspecto educativo, o político, uma vez que apoia-se na ideia de que a linguagem, o ensino e a concepção política estão imbricados na formação do sujeito e, por isso, o professor tem que ter concepção política, saber por que e para que está ensinando.

Desse modo, nas Diretrizes Gerais... a disciplina Português pode ser compreendida em sua natureza política como forma de poder, comprometida com a transformação social, por isso enfatizam que o ensino da língua deve possibilitar a formação do ser crítico, criativo e agente de sua história, capaz de atuar na sociedade em que vive. Para isso, o documento ressalta a necessidade de a escola levar em conta os conhecimentos linguísticos do aluno, valorizá-los e partir deles no processo de reflexão sobre diferentes usos da língua.

É importante valorizar a fala da criança, permitindo, através de diferentes usos da língua a concretização do seu pensamento. Desse modo, ela terá reais condições de desenvolver o seu potencial crítico reflexivo, adquirindo novas formas de expressão, sendo capaz de interagir com seu interlocutor de modo adequado e criativo. (MATO GROSSO DO SUL, 1989, p. 27).

E também enfatiza:

[...] a língua culta é a variedade privilegiada pela sociedade. É por meio dela que se expressa a burocracia do Estado, a literatura e grande parte das produções dos meios de comunicação. Enfim, com o domínio dessa variedade o cidadão tem facilitada sua participação política na sociedade, bem como seu acesso aos bens culturais dessa mesma sociedade.

Portanto, a escola deve ter por compromissos levar o aluno ao domínio dessa variedade - que não é a única, nem a melhor, mas uma dentre tantas, já que entendemos a língua como um conjunto de variedades. A convivência que a escola deve estabelecer entre a língua culta e as variedades dialetais de seus alunos deve ser permeada pelo pressuposto de que levar o aluno ao domínio da norma culta não significa levá-lo a substituir uma por outra, significa, sim, ampliar seu universo de conhecimento, ou seja, a par do domínio que ele já tem da variedade lingüística de seu grupo de origem, que venha também a conhecer a variedade padrão. (MATO GROSSO DO SUL, 1989, p. 36, grifos meus).

Já nas Diretrizes Curriculares..., de 1992, a disciplina Português prioriza a discussão por que e para que ensinar o que e como ensinamos e por que e para que os alunos aprendem o quê e como aprendem, destacando prioritariamente uma concepção de linguagem que emerge "[...] não apenas como uma atividade escolar, mas como uma atividade humana, histórica e social” (MATO GROSSO DO SUL, 1992, p. 13). 
Leitura e produção de textos respondem à discussão formulada, porque de acordo com o documento são meios para vivenciar e refletir sobre os usos da língua.

\begin{abstract}
Em conseqüência, o trabalho a ser desenvolvido deverá se basear no TEXTO, enquanto processo/produto das interações verbais, uma vez que no TEXTO se concretizam as visões de mundo de seus autores e as estratégias escolhidas para produzi-los em função dos objetivos e dos leitores que constituem o processo de interlocução.

Com base nesses aspectos, pode-se pensar o texto como centro do trabalho e/ou conteúdo específico de ensino-aprendizagem da língua portuguesa. De certo modo, em todos os componentes curriculares da escola de $1^{\circ}$ e $2^{\circ}$ graus, trabalhase com textos através dos quais veiculam-se os diferentes conteúdos de ensino. $\mathrm{O}$ que caracteriza a especificidade do trabalho com textos, em Português, é o fato de ele próprio ser tomado como conteúdo de ensino. (MATO GROSSO DO SUL, 1992, p. 16).
\end{abstract}

\title{
O documento Referencial Curricular da Educação Básica da Rede Estadual de
} Ensino/MS (Ensino Fundamental), de 2008, publicado pós-LDB ${ }^{9}$ e pós-PCN ${ }^{10}$, busca seguir o normatizado na esfera federal, ainda que de modo tardio. Seu eixo passa a centrarse nas discussões acerca de alfabetização e letramento; relação entre brincar, estudar e aprender; rotina escolar; existência de diferentes linguagens; tecnologias; diversidade; interdisciplinaridade; transversalidade e avaliação, contemplando as diferentes disciplinas e, também, no desenvolvimento de competências e habilidades que não se limitem apenas na construção de conteúdos. O que se pode ressaltar, nesta análise preliminar, é que o que orienta a discussão sobre o ensino de língua portuguesa neste documento são razões internas à disciplina, inerentes ao desenvolvimento de novos paradigmas no campo das ciências da linguagem e, ainda, a forte influência dos Parâmetros Curriculares Nacionais, sendo quase sua paráfrase.

A disciplina Língua Portuguesa adquire uma dimensão ampla, porque a língua no Referencial Curricular... é considerada “[...] como processo de transformação social, em constante evolução, resultante da conexão entre a linguagem e a vida, contribuindo para o desenvolvimento intelectual dos indivíduos [...]"(MATO GROSSO DO SUL, 2008, p. 26), ou seja, o domínio da língua tem duplo objetivo: instrumento e fim.

Como instrumento, o objetivo do professor é oferecer ao aluno, o mais cedo possível, autonomia para usar a língua no aprendizado. Como fim, tem o objetivo de o professor oferecer ao aluno experiências que lhe permitam conhecer melhor a estrutura e funcionamento da língua, de forma a apreciar a função e utilidade, inclusive como instrumento de desenvolvimento cultural e de lazer. (MATO GROSSO DO SUL, 2008, p. 26).

\footnotetext{
${ }^{9}$ Refiro-me à Lei de Diretrizes e Bases da Educação Nacional no 9.394 de 1996.

${ }^{10}$ Refiro-me aos Parâmetros Curriculares Nacionais publicados em 1997.
}

\begin{tabular}{|l|l|l|l|l|l|}
\hline Interfaces da Educ. & Paranaíba & v. 1 & n. 2 & p. 55-68 & 2010 \\
\hline
\end{tabular}


Em vista disto, o eixo da disciplina centra-se na produção e compreensão de discursos ou no esquema: uso-reflexão-uso, num movimento cíclico. Esse esquema considera a língua nas dimensões gramatical, semântica e discursiva ou pragmática; a diversidade textual; e a variação linguística.

\section{Considerações Finais}

Neste texto busquei apresentar a pesquisa que venho desenvolvendo em pósdoutorado. Os resultados são ainda parciais e frágeis, mas apontam para a necessidade do tema e da abordagem para o avanço da disciplina língua portuguesa em Mato Grosso do Sul, uma vez que as propostas curriculares que estão sendo analisadas sintetizam reformas no ensino, o que “[...] faz referência à mobilização dos públicos e às relações de poder na definição do espaço público" (POPKEWITZ, 1997, p. 18).

Por serem reformas, apenas, fazem parte dos procedimentos governamentais de regulação social e não significam progresso em si mesmas; não significam necessariamente mudanças ou inovações. As mudanças têm, aparentemente, um efeito menos normativo e mais científico e só podem ser julgadas quando incorporadas pelo grupo a que as reformas se dirigem (CHARTIER, 2000).

A despeito disso, o que foi aqui apresentado visa a contribuir tanto para a produção de uma história da disciplina língua portuguesa em Mato Grosso do Sul, do ponto de vista proposto, quanto contribuir para tomada de decisões para melhoria do ensino dessa disciplina no Brasil, oferecendo subsídios para se pensar e se repensar esse ensino, a partir da compreensão histórica desse fenômeno, uma vez que penso como Michel de Certeau (1994) que a história é ambivalente: ao dar lugar ao passado, do mesmo modo dá lugar ao futuro.

\section{Referências}

BIASOTTO, Wilson Valentin; TETILA, José Laerte Cecílio. O movimento reivindicatório do magistério Público Estadual de Mato Grosso o Sul: 1978-1988. Campo Grande: Editora UFMS, 1991.

BOTTO, Carlota. Nova história e velhos dilemas. Revista USP, São Paulo, n. 23, p. 23-33, set/nov. 1994.

BLOCH, Marc. Introdução à História. 4. ed. Sintra: Europa América, s.d. 
CERTEAU, Michel de. A invenção do cotidiano: artes de fazer. 2. ed. Trad. Ephraim F. Alves. Petrópolis: Vozes, 1994.

CHARTIER, Roger. Educação. In.: LE GOFF, Jacques; CHARTIER, Roger; REVELS, J. (Dir.) A nova história. Trad. M. H. Arinto e R. Esteves. Coimbra: Almedina, 1990. p. 160162.

CHARTIER, Anne-Marie. Sucesso, fracasso e ambivalência da inovação pedagógica: o caso do ensino de ciências. Conferência, Belo Horizonte: CEALE, dez. 2000.

CHERVEL, Andre. História das disciplinas escolares: reflexões sobre um campo de pesquisa. Teoria \& Educação, Porto Alegre, n. 02, p. 177-229, 1990.

GERALDI, João Wanderley; SILVA, Lilian Lopes Martin da ; FIAD, Raquel Salek. Linguística, ensino de língua materna e formação de professores. D.E.L.T.A, São Paulo, v. 12, n. 2, p. 307-326, 1996.

JULIA, Dominique. A cultura escolar como objeto histórico. Trad. Gizele de Souza. Revista Brasileira de História da Educação, n. 1, p. 9-44, jan/jul 2001.

MARINHO, Marildes. A oficialização de novas concepções para o ensino de português no Brasil. 2001. 301f. Tese (Doutorado em Linguística) - Instituto de Estudos da Linguagem, UNICAMP, Campinas, 2001.

MATO GROSSO DO SUL. Diretrizes Gerais para o ensino de pré-escolar e de $1^{\circ}$ grau. Campo Grande, MS: Secretaria de Estado de Educação, 1989.

. Diretrizes Curriculares Português, Língua Portuguesa e Literatura Brasileira $\left(1^{\circ}\right.$ e $2^{\circ}$ graus). Campo Grande, MS: Secretaria de Estado de Educação, 1992.

. Referencial Curricular da Educação Básica da Rede Estadual de Ensino/MS

(Ensino Fundamental). Campo Grande, MS: Secretaria de Estado de Educação, 2008.

MORTATTI, Maria do Rosário Longo. Notas sobre linguagem, texto e pesquisa histórica em educação. História da Educação, ASPHE/FaE/UFPel, Pelotas, n. 6, p. 69-77, out. 1999.

. Os sentidos da alfabetização (São Paulo - 1876/1994). São Paulo: Ed. UNESP; Brasília: MEC/INEP/COMPED, 2000a.

MORTATTI, Maria do Rosário Longo. Leitura crítica da literatura infantil. Leitura: teoria \& prática, Campinas, v. 36, p. 11-17, 2000 b.

. Ensino de língua e literatura no Brasil: repertório documental republicano. Marília: FFC/UNESP, 2003. (digitado).

POPKEWITZ, Thomas S. Reforma educacional: uma política sociológica: poder e conhecimento em educação. Trad. Beatriz Afonso Neves. Porto Alegre: Artes Médicas, 1997.

\begin{tabular}{|l|l|l|l|l|l|}
\hline Interfaces da Educ. & Paranaíba & v. 1 & n. 2 & p. 55-68 & 2010 \\
\hline
\end{tabular}


SANTOS, Lucíola Licínio de C. P. História das disciplinas escolares: perspectivas de análise. Teoria \& Educação, Porto Alegre, n. 02, p. 21-29, 1990.

VIEIRA, M. P. A.; PEIXOTO, M. R. C.; KHOURY, Y. M. A. A pesquisa em história. 2. ed. São Paulo: Ática, 1991. (Princípios). 